\title{
A European Perspective on Country Moderation Effects: Environmental Man- agement Systems and Sustainability-Related Human Resource Benefits
}

\author{
Prof. Dr. Marcus Wagner \\ Department of Economics and Business Administration, Julius Maximilians University \\ Stephanstr. 1, 97070 Wuerzburg \\ Tel.: +49-931-318-9046, Fax: +49-931-318-7263 \\ E-mail: marcus.wagner@uni-wuerzburg.de, \\ http://www.bwl.uni-wuerzburg.de/lehrstuehle/bwl8/
}

Secondary affiliation:

Bureau d'Economie Théorique et Appliquée, Université de Strasbourg

61 av. de la Fôret Noire, 68000 Strasbourg

Short biography: Marcus Wagner is full professor and holds of the Chair in Entrepreneurship and Corporate Growth at the University of Wuerzburg. He is associated to the Bureau d'Économie Théorique et Appliquée, Université de Strasbourg. His research interests are entrepreneurship, innovation management and strategic management, often at the intersection with sustainability issues and other long-term societal trends.

Appeared in:

Wagner, M. (2015). A European perspective on country moderation effects: Environmental management systems and sustainability-related human resource benefits. Journal of World Business, 50(2), 379-388. 


\title{
A European Perspective on Country Moderation Effects: Environmental Man- agement Systems and Sustainability-Related Human Resource Benefits
}

\begin{abstract}
Based on a large European dataset of the manufacturing sector, this paper analyses to what degree country-related interaction effects moderate the association of sustainability-related benefits to human resource management and the adoption of environmental management. Focusing on employee satisfaction, it confirms a positive association of the level of employee satisfaction benefits with environmental management system implementation thereby providing cross-national evidence for the frequent argument, that the degree to which environmental management system implementation is associated with human resource related benefits is partly moderated by country level factors related to national culture and regulation.
\end{abstract}

Key words: National Culture, Regulation, Innovativeness, Human Resources, Sustainability 


\section{Introduction}

Sustainability is increasingly gaining momentum in the international context. For example, Scherer et al. (2008) make a plea to explore internal organizational consequences of increasingly political mandates of business firm, specifically suggesting the need to analyze the implications for the human resources function. Similarly, Hiss (2009) suggests that there is heterogeneity across countries in how corporate sustainability and environmental management are adopted within firms. Combining these insights, it becomes clear that differences across countries matter for the effect of HR-related benefits from and hence the extent of environmental management systems (EMS) adoption (Steger et al., 2002). Therefore, an interaction is possible between the HR-related benefits and regulatory and national cultural variables, which reflect institutional differences between countries. Focusing on employee satisfaction as the dependent variable to proxy for HR benefits in general (Turbin \& Greening, 1997; Ramus, 2002; Egri \& Hornal, 2002; Holtom et al., 2008) and accounting for the possible moderating role of national culture and regulation innovativeness, research hypotheses are formulated based on theoretical reasoning and arguments in the literature and in the following tested empirically.

In the literature, corporate sustainability and as part of this environmental management has increasingly moved into the focus of organisational analysis in recent years to explain the actual behaviour of firms with regard to sustainable management as it can be observed under real world conditions (Scherer and Palazzo, 2011). Environmental management systems (EMS) are considered as one important means to integrate aspects of 
environmental management into corporate decision making and environmental management is considered to be one cornerstone of sustainability and sustainable development which the World Commission on Environment and Development defines as "... development that meets the need for the present without compromising the ability of future generations to meet their own needs" (WCED, 1987, p. 54). This means that EMS implementation is often key for corporate sustainability (Kolk, 2010; Schaltegger \& Burritt, 2005; 2010), and as part of this sustainability-oriented human resource (HR) management, defined for the purposes of this paper as a management of human resources that meets the current needs of a firm and society at large without compromising their ability to meet any future needs (Mariappanadar, 2003; Wagner, 2013).

More specifically, employee-related benefits such as heightened work satisfaction have often been suggested as motivations for implementing an EMS (Maignan et al., 1999; Boudreau \& Ramstad, 2005; Cohen, 2010). In this respect Linnenluecke and Griffiths (2010) suggest the need for a sustainability-oriented organizational culture to achieve corporate sustainability and point to staff training and the human relations model as an important theoretical antecedent for this. In doing so, they provide further theoretical arguments for the role of employee-related benefits for the implementation of EMS.

Whilst such streams of work significantly contributed in terms of conceptual clarification and refinement, empirical evidence has not developed as much, partly of course since inherently it can only follow on theoretical advancements. In light of this, the intersection of corporate sustainability, $\mathrm{HR}$ and international institutional variation emerges as an important focal area of empirical research to test at least part of the theoretical propositions developed and to provide guidance to future theorizing. 
Most importantly in the context of this paper, even though there is some countryspecific empirical evidence that sustainability-oriented HR management associates with EMS (e.g., Hamschmidt \& Dyllick, 2001; Wagner, 2011) this has not been explored empirically across countries, where additional interaction with national cultures or differences in regulation need to be accounted for. In fact, Ehnert et al. (2014) stress the a large research gap and need for on a large-scale, quantitative data on sustainabilityoriented HR management due to little empirical work done on the topic to date and identify the most significant challenges in this respect across cultural contexts. Therefore, in the remainder, this paper addresses these latter two aspects by developing research hypotheses on how country differences can affect the link of HR and EMS implementation and by testing these empirically and quantitatively on a large scale in an European context.

\section{Literature Review and Development of Research Hypotheses}

This section shall anchor the analysis provided in the remainder of this paper in extant literature and derive research hypotheses. As a starting point, a secular trend can be observed since the 1970's towards stronger reflection of social issues and concerns for the natural environment in firms' activities (Costantini \& Mazzanti, 2012; Martín-Tapia et al., 2008; 2010).

Sustainability-oriented HR management (and as part of this "green" HR which can be understood as that part of the former which relates to corporate environmental protection activities) has had little relevance in the past because the natural environment was not a significant cost factor given that much of the pollution cost could be externalized due to weak or non-existing regulations. Once regulations tightened, many firms were 
initially aiming for quick technical solutions using end-of-the-pipe approaches and other separated environmental management solutions. During this phase again the HR function had little incentives to address the issue because it was not clear how this could contribute to value creation in the firm.

Only when it emerged, that complementary organizational changes can significantly improve the performance of technical solutions in the context of environmental management and corporate sustainability in general and when in parallel a "war for talent" started in developed economies due to of skilled labor caused by long-term demographic trends towards lower birth rates, sustainability-oriented HR management became more prevalent (Christmann, 2000). This was further supported by a parallel trend of employees becoming increasingly more environmentally conscious and thus expecting from employers more serious attempts to integrate corporate social responsibility concerns in all their structures and activities (Crane et al., 2008).

The perspective that emerges from these considerations of temporal evolution and especially the increasing integration of corporate sustainability within firms as a means to address a wider stakeholder audience holds particular relevance for the link of HRrelated benefits and environmental management. Specifically, employee satisfaction is said to be positively affected by EMS implementation (Haugh \& Talwar, 2010; Ehnert \& Harry, 2012). From a resource-based perspective, worker morale is an important production input ultimately creating value added (Huslid, 1995; Martin-Tapia et al., 2008; 2009). To the degree that firm's perceive that benefits from EMS implementation exist that raise employee satisfaction and hence ultimately productivity and profitability, implementation levels should be higher, ceteris paribus, leading to the following hypothesis: 
Research hypothesis 1: After controlling for other relevant factors, there is a significant positive association of firm-specific private benefits from employee satisfaction with the level of EMS implementation in European firms.

Consistent with this hypothesis Fassina et al. (2008) in a single country study find that employee satisfaction associates positively with citizenship behavior in firms, in turn raising the question if this is consistently the case across countries or whether institutional differences e.g. relating to national culture or regulatory regime as well as firmspecific conditions with regard to these need to be accounted for.

As concerns the latter, recent contributions in management research have increasingly highlighted the role of firms as political actors (Scherer \& Palazzo, 2011; Scherer et al., 2014). Related to this conceptual works stress the relevance of accounting for institutional differences, especially in the context of international business, given an unhalted trend of globalization (Scherer \& Palazzo, 2008; Bondy et al., 2012; Brammer et al., 2012).

Whilst in itself undisputed, the notion of a process of globalization is somewhat at odds with the notion of historically-grown, path-dependent (national) institutional environments that cannot be adjusted or changed at short notice. Therefore it is likely that (given and different) institutional environments characterized by different national cultures or regulatory regimes affect the extent to which corporate sustainability initiatives such as EMS implementation are triggered by a given private benefit to the firm.

The introduction of EMS can in this respect also be understood as a form of selfregulation driven by weakening nation states in the wake of globalization (Scherer \& Palazzo, 2008). National institutions are often rooted in the notion that firms' sole responsibility is their profitability (Friedman, 1970). This leads them to frame firm ac- 
tions as rent-seeking lobbying or philanthropy (Carroll, 1979), whereas in reality firm action often addresses a governmental void or inability for e.g. regulation of novel issues, resulting in the above notion of firms as political actors.

However, the degree to which firms are inclined to pursue self-regulation activities such as EMS implementation depends on the one hand on a firm's international orientation (since effects from weakening nation states in light of globalization is strongest in international contexts). At the same time and independent of international orientation larger firms are more visible to stakeholder groups (Bowen, 2000; 2002) and thus benefit more from self-regulation, e.g. because isomorphic pressures to mimic others in the same size category is stronger with higher visibility (Matten and Moon, 2008; Preuss et al., 2009; Scherer et al., 2009). Also larger firms possess more resources and targeted capabilities for and have more economies of scale and scope from self-regulation. In sum these considerations lead to the following hypothesis:

Research hypothesis 2: After controlling for other relevant factors, there is a moderating effect of market internationalization on the association of firm size with the level of EMS implementation in European firms.

As concerns the role of employee satisfaction-related benefits for EMS implementation across countries and under different institutional circumstances in terms of e.g. national cultures or regulatory regimes the remainder of this section derives hypotheses, based on extant literature, on how firm characteristics interact with country-specific differences. As a starting point, benefits for employee satisfaction from corporate citizenship have in general been acknowledged in the literature, especially in the context of highperformance work systems where they are ultimately proposed to improve the economic performance of the firm (Gavin \& Maynard, 1975; Huslid, 1995; Riordan et al., 1997; 
Turbin \& Greening, 1997; Jabbour et al., 2008). Yet, whilst several studies have assessed the link of the assessment of satisfaction of individual employees with EMS implementation (Cordano \& Frieze; Cordano et al., 2004), empirical analyses at the level of aggregate benefits to the firm as a whole are rare, and especially so in a multi-country context.

Given the relevance of pursuing a comprehensive set of corporate sustainability activities, what matters is a long-term orientation, since otherwise firms may be perceived as "green-washing". However, long-term orientation is differing across countries and national institutions. At the country level, long-term orientation (precisely defined as the degree to which the members of a culture or society orient their thinking towards the more distant future versus today) can be measured in terms of the indices in Hofstede (2001). Long-term orientation defined in this way does not concur with sustainability. For example Germany has a value of 31 which is much lower than the values of China (118) and Japan (87). This is because long-term orientation also accounts for thrift and persistence and in terms of sustainability one might not judge the latter two countries being necessarily dominant over the former country.

Park and Ghauri (2014) find that stakeholder pressures drive and moderate the adoption of corporate social responsibility practices for small and medium-sized subsidiaries. Since long-term orientation can also be understood as a surrogate measure for such pressures, an interaction with the benefits from employee satisfaction is to be expected. Given the dual notion of long-term orientation described above, the interplay of firm's perceived benefits from employee satisfaction with long-term orientation, and hence the direction of any direct and interaction effects is however an empirical question. Overall, these considerations lead to the following hypotheses: 
Research hypothesis 3a: After controlling for other relevant factors, there is a significant association of the degree of long-term orientation with the level of EMS implementation in European firms.

Research hypothesis 3b: After controlling for other relevant factors, there is a moderating effect of long-term orientation on the association of firm-specific private benefits from employee satisfaction with the level of EMS implementation in European firms.

Next to the Hofstede (2001) dimensions, the World Values Survey provides another incommensurable classification by distinguishing a secular-rational values dimension on which one extreme is characterized by importance of religion, deference to authority, absolute standards and traditional family values, and the opposite, secular-rational, extreme by opposing preferences (Inglehart \& Welzel, 2005).

High values on the secular-rational dimension should associate positively with EMS implementation since they correspond to higher openness for self-regulatory instruments that are focused on efficiency and improved performance (Haugh \& Talwar, 2010). Compared to this, notions of conventional command and control regulation are more consistent with traditional notions corresponding to low values on the secularrational dimension of the World Values Survey.

The second main dimension relates to a polarization between survival and selfexpression, where the former emphasizes economic and physical security, and the latter perceived well-being and subjective quality of life. Thus, a negative interaction effect of this with human resource benefits can be expected. This is because if for a country the level of self-expression is high, this associates with strong desire for personal freedom and a corresponding dislike for absolute norms. Therefore, human-resource related ben- 
efits should lead to a less strong effect on EMS implementation here than in the case of countries having low self-expression levels. In sum, this leads to the following hypotheses:

Research hypothesis 4a: After controlling for other relevant factors, there is a significant positive association of the degree of secular-rationality with the level of EMS implementation in European firms.

Research hypothesis 4b: After controlling for other relevant factors, there is a negative moderating effect of the degree of self-expression on the association of firm-specific benefits from employee satisfaction with the level of EMS implementation in European firms.

Regulation innovativeness refers to the notion of creative approaches to environmental regulation that leaves discretion for firm-individual initiatives (WEF et al., 2000). More specifically, regulation innovativeness is defined as degree to which regulation is building on novel and economic instruments such as Pigou or standard-price based taxes, voluntary or negotiated agreements or tradable permit or emission trading systems. As outlined earlier, a regulatory gap exists in that national institutions are not easily reconcilable with social and environmental challenges originating beyond the nation stage (such as climate change). They thus do not lend themselves easily to national regulation (Scherer et al., 2009), in turn opening up potential for transnational self-regulation of corporations. Therefore, a positive direct effect of higher regulation innovativeness can be expected on corporate self-regulation such as EMS implementation. This is because as defined above, higher levels of regulation innovativeness imply a less strong orienta- 
tion towards command-and-control regulation and thus leave more scope for novel approaches of self-regulation such as EMS implementation.

Yet at the same time, in increasingly globalised employment markets, maintaining talent becomes challenging, which some have argued can be eased by signaling good corporate citizenship, e.g. by implementing an EMS (Tarique \& Schuler, 2010). Therefore, high regulation innovativeness as defined above should also amplify firm-internal support in terms of HR-related benefits suggesting in turn a positive interaction effect of this latter variable with regulation innovativeness. This leads to the following two hypotheses:

Research hypothesis 5a: After controlling for other relevant factors, there is a positive association of regulation innovativeness with the level of EMS implementation in European firms.

Research hypothesis 5b: After controlling for other relevant factors, there is a positive moderating effect of regulation innovativeness on the association of firm-specific benefits from employee satisfaction associates with the level of EMS implementation in European firms.

Testing the derived research hypotheses empirically to provide insights on the appropriateness of current conceptual models and to address the salient research gaps suggested by Ehnert et al. (2014) is the objective of the remainder of the paper.

\section{Data and Method}

To analyse the above research hypotheses, a survey amongst European manufacturing firms was carried out in Belgium, France, Germany, Hungary, the Netherlands, Norway, 
Sweden, Switzerland and the United Kingdom. The survey asked questions on the implementation of environmental management systems, the role of environmental management for different competitiveness dimensions, and relevant firm-specific variables. The questionnaire was built on earlier surveys and a review by several experts in the field ensured that all items were easily understandable and had content validity, time for completion was acceptable and that face validity was also high.

The questionnaires were mailed to the general or environmental manager of a company and suggested that it should be forwarded as necessary to the person most knowledgeable to answer it. In some cases, the questionnaire was therefore completed by the quality manager or personnel manager. Responses to the survey were received from over 2000 firms, for which Table A1 in the Appendix provides a sample breakdown by country and industry. The response rate of $26.1 \%$ is above average for the field of business administration which strengthens the analysis and conclusions (Cote \& Buckley, 1987).

To assess the representativeness and response bias, the procedures suggested by Armstrong and Overton (1977) as well as Homburg and Bucerius (2006) are adopted, as far as possible. Comparing the earliest and latest $10 \%$ of respondents in terms of their characteristics and response behaviour no significant differences in the mean values of the responses of all variables used in the analysis were found except for late responding firms being significantly smaller in some countries (e.g. Germany). As well, as can be seen from the descriptive statistics in Table A2 there is large variation across the responses in indicating that also firms less active in terms of environmental management did respond to the survey. Whilst these findings indicate that response bias is unlikely in the data, two procedures were additionally employed to reduce any remaining, especially method-related bias. 
Firstly, Harman's single-factor test was applied to establish whether one single factor accounting for most of the variance in the data could be identified from the non-rotated solution of a factor analysis. This solution consists of 35 factors of which 18 have Eigenvalues larger than unity. The first three factors explain $8.3 \%, 4.8 \%$ and $4.6 \%$, respectively. All remaining factors with Eigenvalues greater than one explain between $2.1 \%$ and $4.1 \%$ of the variance in the data. This is strong evidence against the existence of one general factor accounting for most of the variance in the data.

Secondly, procedurally different response formats were used, the anonymity of respondents was ensured, question order was counter-balanced and scale items were improved, especially during the pre-test phase of the survey. All these steps were aimed at reducing socially desirable responses and item ambiguity. For the sake of keeping the anonymity of respondents, it was not generally possible to pursue two other procedural remedies, namely obtaining assessments from different respondents and separating measurements. However the instructions provided for the survey (in particular to ask for the most knowledgeable person to answer it) and the way the survey was implemented made it possible that even these two remedies could in principle be applied by respondents.

To address the research hypotheses formulated earlier, an index of EMS implementation is used as the dependent variable. Whilst earlier works have measured EMS implementation based on dummy variables capturing whether or not firms have achieved certification or verification according to ISO 14001 or the EU Eco-Management and Auditing Scheme this seems problematic, because approaches rooted in institutional economics argue the existence of incentives for firms to behave opportunistically as concerns case of EMS certification (Ziegler \& Rennings, 2004; Rehfeld et al., 2007). Opposed to this 
the resource based view (Wernerfelt, 1984) suggests that EMS implementation measured independent of certification reflects the development of strategic resources and competitive advantages. Therefore, to evaluate EMS implementation, an index variable is used that measures a number of relevant environmental management activities as was done in earlier research (Wagner, 2013). The relevant activities were existence of a written environmental policy, procedure for identification and evaluation of legal requirements, initial environmental review, definition of measurable environmental goals, existence of a programme to attain measurable environmental goals, clearly defined responsibilities, environmental training programme, environmental goals being part of a continuous improvement process, separate environmental/health/safety report or environmental statement and existence of an audit system to check environmental programme. The listed activities are those required by the dominant EMS standards such as ISO 14000 and EMAS and which are therefore common to EMS across industries (Florida \& Davison, 1995; Wagner, 2009). The EMS index correlates well with a variable asking firms on a four-point scale whether they had implemented an EMS with the categories 'EMS fully implemented', 'implementation in progress', 'implementation considered ' and 'no implementation at all' which certifies its face and content validity (Wagner, 2009).

The central explanatory variables for testing the above hypotheses relate employee satisfaction (as the independent variable), market orientation, national culture (as proxied by long-term orientation and the World Values Survey variables) and regulation innovativeness. Employee satisfaction as a proxy for sustainability-related human resource benefits in general is measured based on a Likert scale rating the environmental management effects of the former on five levels, namely "very negative", "negative", "neu- 
tral", "positive" and "very positive". Employee satisfaction has been suggested as a crucial dimension of environmental management benefits (Knox \& Maklan, 2004) and there is generally a high association with similar dimensions such as employee motivation, retention/avoidance of turnover, recruitment/organisational attractiveness and labour productivity (March \& Simon, 1958; Hackman \& Oldham, 1980; Huslid, 1995; Turbin \& Greening, 1997). ${ }^{1}$

As introduced in the section developing hypotheses, national cultural differences are addressed in two variants in the empirical analysis. Firstly, they can be measured based on the work of Hofstede (2001) by means of a variable referring to long-term orientation. $^{2}$ Alternatively, national cultural differences relating to our focus on employee satisfaction and EMS benefits can be addressed through the factors of the World Values Survey (Inglehart \& Welzel, 2005) and this is done in a variant of the analysis to avoid methodological artefacts due to the incommensurability of both schemes.

The World Values Survey derives on the one hand the secular-rational values dimension as described characterized by relevance of religion and authority, absolute standards and family values, and the opposite, secular-rational extreme by opposing preferences (Inglehart \& Welzel, 2005). The second values dimension referring is to survival and selfexpression, with high values corresponding to lower relevance economic and physical security, and higher importance of well-being and quality of life.

\footnotetext{
${ }^{1}$ Employee satisfaction is measured at the organizational level because, Hofstede's national culture variables can be safely linked to firm data, but not to the level of individual employees (Kirkman et al. 2006). ${ }^{2}$ Long-term orientation as defined and measured in terms of the indices in Hofstede (2001) is used to proxy national culture since it is expected to produce the strongest moderation effect compared to individualism, masculinity, uncertainty avoidance and power distance as the other dimensions in Hofstede's framework. As detailed when deriving hypotheses, this is because long-term orientation (defined as the degree to which the members of a culture or society orient their thinking towards the more distant future versus today) is in principle linked more strongly to sustainability-related benefits than other dimensions.
} 
As explained earlier, the regulatory framework is measured through a variable on the innovativeness of a country's (environmental) regulation since the level of innovativeness supports by itself more strongly the implementation of novel solutions and voluntary actions such as EMS (WEF et al., 2000; Rugman \& Verbeke, 1998; Levy \& Prakash, 2003). Data is taken from WEF et al. (2000) who measure the variable in a comparable manner across countries for 1999 which is the last year for which it was available before the survey took place in 2001. Market internationalization is operationalized as an ordinal variable assessing whether the most relevant market for a surveyed firm is local (coded: 1), regional (coded: 2), national (coded: 3, European (coded: 4) or worldwide (coded: 5).

Next to the central explanatory variables, several other control variables are also included. In line with Wagner (2013), additional benefit categories are included in a variant of the model. These are cost savings, better insurance conditions, improved access to bank loans, improved sales, market share gains, productivity increases, all rated in the same manner as the independent variable. It is expected that they also correlate positively with environmental management system implementation.

As basic firm characteristics, size in terms of the logarithm of the number of employees (Bowen, 2002; Darnall, 2003), firm status in terms of a dummy variable (yes or no) if the firm is completely independent (Berrone et al., 2010), and the existence of a QMS (binary dummy variable, yes or no) is included in the analysis as control variables, also because EMS can be understood as an organisational innovation (Laforet, 2013).

Also incorporated in the model is the market development trend in the main market (measured on a 5-point scale ranging from "market is considerably decreasing" to 
"market is considerably increasing") since environmental management benefits from high growth and munifience (Russo \& Fouts, 1997).

Finally, overall business performance (measured on a five-point scale ranging from "revenues are well in excess of cost" to "revenues are so low as to cause large losses") is included as a control variable in the model to account for an influence of slack resources and similar effects (Waddock \& Graves, 1997; Surroca et al., 2010).

Since EMS index is only based on items that are applicable in all industries included in the sample and generic in the sense that they are in core elements of the EMS standards ISO 14001 and EMAS), industry dummies would not have to be included in the analysis in the analysis. However, to still address differences that may exist in practice, industry dummies are included as control variables. ${ }^{3}$

All models are estimated using ordinary least squares (OLS) and ordered probit as well as ordered logit cross-sectional regressions with heteroskedasticity-corrected standard errors. In the case of ordinal variables, ordinal choice models are econometrically more appropriate since for this category of variables ordinary least squares regressions are only approximately correct and might even lead to biased and or inefficient estimations (Long, 2002). The two possible variants of ordinal choice models are ordered logit or ordered probit models, which both overcome the problems with OLS. Given this, all specifications are estimated using both models since proceeding like this would reveal any differing results and would not impose any restrictions in preferring one model over the other. Since the ordered probit and logit models are more appropriate given the or-

\footnotetext{
${ }^{3}$ Note that because long-term orientation, World Value Survey dimensions and regulation innovativeness are country-specific, individual country dummies could not be entered in the estimation, since this would have introduced severe multi-collinearity.
} 
dinal dependent variable, only results for these are reported here, but the results for OLS (which are qualitatively the same) are available on request.

Inspection of correlations in Table A2 reveals that multi-collinearity is not an issue for the analysis as is confirmed by the variance inflation factors ranging from 1.07 to 5.05 for individual variables with the average across all models being 1.92. Interaction terms between employee satisfaction and, respectively, regulation innovativeness and longterm orientation are mean-centered on all occasions.

\section{Results}

In Tables 1 and 2 below results are initially shown and subsequently discussed for the models with Hofstede's long-term orientation as the national culture measure, and the corresponding interaction terms with employee satisfaction, respectively.

\section{\{insert Table 1 about here\}}

As Table 1 shows, employee satisfaction is strongly significant and positively associated with the EMS index, which confirms research hypothesis 1 and earlier single-country evidence (Wagner, 2013) at a cross-national level. Of other benefits, only the association with increased sales is significant. Comparing coefficients for the variables it becomes clear that the effect of employee satisfaction is also economically more pronounced than that of sales increases and the other explanatory factors included. This suggests that benefits from environmental management that relate to human resources are relatively more relevant than other competitiveness aspects. Direct industry effects 
are very limited, with only the wood, paper, energy and chemical industries being significant, but not the remaining eleven industries. ${ }^{4}$

\section{\{insert Table 2 about here\}}

As Table 2 reporting results for the model including interactions in conjunction with Table 1 shows, also research hypothesis 2 is confirmed, given the interaction of market orientation and firm size is significant and positive. Furthermore, long-term orientation is not significant, which disconfirms the direct effect in the research hypothesis $3 \mathrm{a}$, but since regulatory innovativeness is significantly associated with the EMS index, the direct effect in research hypothesis $5 \mathrm{a}$ is supported. Turning to the other interaction effects addressed in research hypotheses $3 \mathrm{~b}$ and $5 \mathrm{~b}$, Table 2 shows that no interaction effect exists for long-term orientation with employee satisfaction.

As for Table 1, all results are identical for both, the ordered probit and ordered logit specification which suggests that empirically these choices are equally suitable. Also, the control variables remain unchanged in the model with interaction effects and the industry effects being as before, and those for the energy and chemical industries being most pronounced. This confirms the expectation that in these highly-polluting industries environmental management system implementation is most widespread, as has been shown in earlier work (Florida \& Davison, 1995; Wagner, 2013).

\footnotetext{
${ }^{4}$ These results remain the same in all other model specifications reported in Tables 2 to 4 . Also, the results remain unchanged if the benefits not related to human resources, such as heightened sales, increased market share and productivity, reduced cost and financial risk and improved insurance conditions are not included but explanatory power is higher when including them. This also applies to the other Tables 2 to
} 4. 
\{insert Table 3 about here\}

Tables 3 and 4 show results for the operationalization of national culture by means of the World Value Survey data. Turning to Table 3 and thus the model using World Value Survey variables but not including interaction effects, as before a strongly significant positive association of employee satisfaction with the EMS index is found that maintains the support for research hypotheses 1 . Furthermore, the effects of the control and other benefit variables as well as the industry effects (except for the wood industry dummy) remain unchanged compared to the models estimated in Tables 1 and 2. For secular-rational value orientation as the national culture variable a positive and significant effects exists, which confirms research hypothesis $4 a$.

\section{\{insert Table 4 about here\}}

In the model in Table 4 using the World Value Survey variables and including interaction effects all direct effects remain unchanged in terms of direction, significance and order of magnitude compared the other models estimated. As concerns the interaction terms, a significant effect of the interaction of market orientation and firm size is found which confirms again research hypothesis 2 . Also, a negative effect for the interaction of survival/self-expression values and employee satisfaction, and a positive effect for the interaction of regulation innovativeness and employee satisfaction are found. Both are in the expected direction and thus support, respectively, the research hypotheses $4 \mathrm{~b}$ 
and $5 b .{ }^{5}$ In summary therefore, the whole system of research hypotheses is largely confirmed, as is visualised in the following Table 5.

\section{\{insert Table 5 about here\}}

\section{Conclusions and Discussion}

This paper tested several research hypotheses relating to whether EMS implementation renders competitive benefits for HR management and what factors moderate such an effect for a large sample of European firms to address crucial research gaps identified in extant literature (Ehnert et al., 2014). In addition to this, it contributes by combining direct and moderating effects as requested in systematic reviews on cultural variables and by focusing on the least used dimension of the Hofstede model (Kirkman et al., 2006). ${ }^{6}$ Furthermore the paper contributes by following calls to compare this still valid model with another model, namely the World Value Survey (Smith \& Bond, 1999).

The paper also contributes by confirming that the observed benefits are in fact ubiquitous and not mere country-specific effects, which is highly relevant for the recent international initiatives on teaching environmental management, especially as concerns the coordination of different corporate functions as a means to improve corporate environmental performance (United Nations, 2011; Matten \& Moon, 2004). The analysis further revealed that HR-related benefits are the most important direct determinant for EMS implementation, matched only by increased sales with an effect of partly similar

\footnotetext{
${ }^{5}$ Interaction effects remain unchanged if long-term orientation is added to this model, as do all significant direct effects. As indicted in footnote 4, results remain also qualitatively unchanged in model variants excluding other benefits. The results are also qualitatively stable if models are estimated instead with OLS. ${ }^{6}$ For example in the review by Kirkman et al. (2006) only five empirical studies using long-term orientation are identified, with studies for the other four Hofstede dimensions being in the range of 35 to $>100$.
} 
economic magnitude. However none of the other six benefits such as cost reductions were found to be significant. Whilst this finding fits with the recent trend of sustainability becoming a more strategic and competitively relevant theme for firms and business practice (Ehnert, 2009), large-scale as well as cross-country evidence going beyond anecdotal support was so far missing for this claim, a gap which is addressed by this analysis.

Concerning country-related cultural values, Hofstede's long-term orientation is found to have no direct or indirect effect, whereas the secular-rational variable of the World Values Survey is found to have a positive direct effect, which is in the direction hypothesized. Opposed to this, moderation effects could be identified for the self-expression variable of the World Value Survey and for regulation innovativeness, respectively. Thus, the findings also confirm moderating effects from country-level parameters, in turn supporting calls in past systematic reviews for simultaneously addressing direct and moderating affects (Kirkman et al., 2006).

More specifically in this respect, in the models with interactions a negative interaction effect of the self-expression variable with human resource benefits is found which is consistent with the direction hypothesized, that is, if for a country the self-expression variable level is high, then it associates with high desire for personal freedom and a corresponding dislike for absolute norms. Therefore, human-resource related benefits should lead to a stronger effect on EMS implementation in the case of countries with low self-expression levels and this is supported by the large-scale empirical analysis done here.

As concerns the effect of regulation innovativeness, in the models with long-term orientation as national culture variable a significant association with the dependent variable is 
found, confirming a direct effect. In addition to this, in the models using the World Value Survey variables to measure national culture an additional positive moderating effect is found in the hypothesized direction. Both findings are consistent with earlier research suggesting that regulation can have both, direct as well as moderating effects (Chan, 2010), depending on the national culture aspect put into focus. They also underscore again the need of including simultaneously direct and moderation effects, also for geographic, cultural and institutional variables more generally, which also indicates an important direction of future research.

Finally, this research underscores that firm size matters directly and in its interaction with market internationalization for EMS implementation. In summary therefore, the results thus confirm the finding of Hiss (2009) that environmental management needs to be perceived by managers as being contingent on regulatory and geographic contexts and their cultural and institutional correlates, but simultaneously highlight the relevance of the germane HR-sustainability link. This suggests another important alley for future research, namely to analyse in more detail the relative role of the benefit-related factors for implementation. For example it could be that whilst early on environmental management activities where often implemented by quality managers because of the similarity of the relevant international standards underlying both domains (ISO 14001 and ISO 9001, for example), increasingly environmental management has emancipated itself within the firm and is today managed by separate units that are less guided by quality management philosophies but more so by broader notions of corporate sustainability or even HR-related needs of global talent sourcing? This is an area which would certainly merit future investigation, since such a shift would imply an important change in the perception of benefit categories. 
Another area that would merit future research is the question of ecological effects from a more strategic integration of $\mathrm{HR}$ and environmental management. From a societal point of view the main objective of environmental management activities in firms should be the reduction of environmental burdens, yet it is not obvious, why this objective should be perfectly aligned with the objective of generating HR benefits from EMS implementation. Opposed to this, evidence has been provided that environmental management activities in companies tend to be of limited ecological effect (Emerson, 1996; Hamschmidt \& Dyllick, 2001) and future research should clarify under which circumstances this is causally related to a focus on deriving HR benefits from environmental management activities.

\section{Appendix}

\{insert Table Al about here\}

\{insert Table A2 about here\}

\section{References}

Armstrong, J. S., \& Overton, T. S. (1977). Estimating non-response bias in mail surveys. Journal of Marketing Research, 14, 396-402.

Berrone, P., Cruz, C., Gomez-Mejia, L.R., \& Larraza-Kintana, M. (2010). Socioemotional wealth and corporate responses to institutional pressures: do family-controlled firms pollute less. Administrative Science Quarterly, 55(1): 82-113. 
Bondy, K., Moon, J., \& Matten, D. (2012). An institution of corporate social responsibility (CSR) in multi-national companies (MNCs): form and implications. Journal of Business Ethics, 111 (2): 281-299.

Boudreau, J. W., \& Ramstad, P. M. (2005). Talentship, talent segmentation, and sustainability: A new HR decision science paradigm for a new strategy definition. Human Resource Management, 44: 129-136.

Bowen, F. (2000). Environmental visibility: A trigger of green organizational response?, Business Strategy and the Environment, 9, 92-107.

Bowen, F. E. (2002). Does size matter? Organizational slack and visibility as alternative explanations for environmental responsiveness. Business and Society, 41, 118-124.

Brammer, S., Jackson, G. \& Matten, D. (2012). Corporate Social Responsibility and Institutional Theory: New Perspectives on Private Governance. Socio Economic Review, $10(1): 3-28$.

Carroll, A.B. (1979). A three-dimensional conceptual model of corporate performance. Academy of Management Review, 4(4): 497-505.

Chan, R.Y.K. (2010). Corporate environmentalism pursuit by foreign firms competing in China. Journal of World Business, 45(1): 80-92.

Crane, A., Matten, D., \& Moon, J. (2008). Ecological Citizenship and the Corporation: Politicizing the New Corporate Environmentalism. Organization \& Environment, 21(4): 371-389.

Christmann, P. (2000). Effects of "Best Practices" of Environmental Management on Cost Advantages: The Role of Complementary Assets. Academy of Management Journal, 43(4): 663-680. 
Cohen, E. (2010). CSR for HR: A necessary partnership for advancing responsible business practices. Sheffield: Greenleaf.

Cordano, M., \& Frieze, I.H. (2000). Pollution Reduction Preferences of U.S. Environmental Managers: Applying Ajzen's Theory of Planned Behavior. Academy of Management Journal, 43(4): 627-641.

Cordano, M., Frieze, I.H., \& Ellis, K. (2004). Entangled Affiliations and Attitudes: An Analysis of the Influences on Environmental Policy Stakeholders' Behavioral Intentions. Journal of Business Ethics, 49: 27-40.

Costantini V., \& Mazzanti M. (2012). The Dynamics of Economic and Environmental Systems. Innovation, Policy and Competitiveness. Heidelberg: Springer.

Cote, J.A, \& Buckley, M.R. (1987). Estimating trait, method and error variance: generalizing across 70 construct validation studies. Journal of Marketing Research, 24, 315318.

Darnall, N. (2003). Why firms certify to ISO 14001: An institutional and resource-based view. Academy of Management Best Paper Proceedings, ONE, A1-A5.

Egri, C. P., \& Hornal, R. C. (2002). Strategic environmental human resource management and perceived organizational performance: An exploratory study of the Canadian manufacturing sector. In S. Sharma \& M. Starik (Eds.), Research in corporate sustainability: The evolving theory and practice of organizations in the natural environment (pp. 205-236). Boston: Edward Elgar.

Ehnert, I., Harry, W., Zink, K. (2014) The future of sustainable HRM. In: Ehnert, I., Harry, W. \& Zink, K. (Eds.), Sustainability and Human Resource Management - Developing sustainable business organizations (pp. 423-442), Heidelberg: Springer. 
Ehnert, I. (2009). Sustainable human resource management: A conceptual and exploratory analysis from a paradox perspective. Heidelberg: Springer.

Ehnert, I., \& Harry, W. (2012). Recent Developments and Future Prospects on Sustainable Human Resource Management: Introduction to the Special Issue. Management Revиe, 23(3): 221-238.

Emerson, T. (1996). Global warming should make HR people sweat. People Management, 2(6), 21.

Fassina, N.E., Jones, D.A., \& Uggerslev, K.L. (2008). Relationship Clean-Up Time: Using Meta-Analysis and Path Analysis to Clarify Relationships Among Job Satisfaction, Perceived Fairness, and Citizenship Behaviors. Journal of Management, 34: 161-188.

Florida, R., \& Davison, D. (1995). Gaining from Green Management: Environmental Management Systems Inside and Outside the Factory. California Management Review, 43(3): 64-84.

Friedman, M. (1970). The social responsibility of business is to increase its profits. New York Times, Sept. 13: 122-126.

Gavin, J.F., \& Maynard, W.S. (1975). Perceptions of corporate social responsibility. Personnel Psychology, 28: 377-387.

Hackman, J.R., \& Oldham, G.R. (1980). Work Redesign. Reading: Addison-Wesley. Haugh, H. M., \& Talwar, A. (2010). How do corporations embed sustainability across the organization?. Academy of Management Learning \& Education, 9(3): 384-396.

Hamschmidt, J., \& Dyllick, T. (2001). ISO 14001: profitable? Yes! But is it ecoeffective?. Greener Management International, 34: 43-54. 
Hiss, S. (2009). From Implicit to Explicit Corporate Social Responsibility. Business Ethics Quarterly, 19(3): 433-451.

Hofstede G. (2001). Culture's Consequences (2nd edn). Sage: Thousand Oaks.

Holtom, B.C., Mitchell, T.R., Lee, T.W., \& Eberly, M.B. (2008). Turnover and Retention Research: A Glance at the Past, a Closer Review of the Present, and a Venture into the Future. Academy of Management Annals, 2(1): 231-274.

Homburg, C., \& Bucerius, M. (2006). Is speed of integration really a success factor of mergers and acquisitions? An analysis of the role of internal and external relatedness. Strategic Management Journal, 27(4): 347-368.

Huslid, M. (1995). The impact of human resource management practices on turnover, productivity, and corporate financial performance. Academy of Management Journal, 38(3): 635-672.

Inglehart, R., \& Welzel, C. (2005). Modernization, Cultural Change and Democracy New York: Cambridge University Press.

Jabbour, C.J.C., Santos, F.C.A., \& Nagano, M.S. (2008). Environmental management system and human resource practices: is there a link between them in four Brazilian companies?. Journal of Cleaner Production, 16(17): 1922-1925.

Kirkman, B.L., Lowe, K.B. \& Gibson, C.B. (2006). A quarter century of Culture's Consequences: a review of empirical research incorporating Hofstede's cultural values framework. Journal of International Business Studies, 37: 285-320.

Knox, S., \& Maklan, S. (2004). Corporate Social Responsibility: Beyond Investment Towards Measuring Outcomes. European Management Journal, 22(5): 508-515.

Kolk, A. (2010). Trajectories of sustainability reporting by MNCs. Journal of World Business, 45(4): 367-374. 
Laforet, S. (2013). Organizational innovation outcomes in SMEs: Effects of age, size, and sector. Journal of World Business, 48(4): 490-502.

Levy D.L, \& Prakash A. (2003). Bargains old and new: multinational corporations in global governance. Business and Politics, 5(2): 131-150.

Linnenluecke, M.K., \& Griffiths, A. (2010). Corporate sustainability and organizational culture. Journal of World Business, 45(4): 357-366.

Long, J.S. (2002). Regression models for categorical and limited dependent variables. Thousand Oaks: Sage.

Maignan, I., Ferrell, O.C., \& Hult, G.T.M. (1999). Corporate Citizenship: Cultural Antecedents and Business Benefits. Journal of the Academy of Marketing Science, 27(4): 455-469.

March, J.G., \& Simon, H.A. (1958). Organizations. New York: John Wiley.

Mariappanadar, S. (2003). Sustainable human resource strategy: The sustainable and unsustainable dilemmas of retrenchment. International Journal of Social Economics, 30(8): 906-923.

Martin-Tapia, I., Aragón-Correa, J.A., \& Llamas-Sánchez, R. (2008). The relationship between high performance work systems and proactive environmental management. In: S. Sharma, M. Starik, R. Wüstenhagen \& J. Hamschmidt (Eds.), Advances on Research in Corporate Sustainability (pp. 197-225). Boston/Cheltenham: Edward Elgar.

Martin-Tapia, I., Aragon-Correa, J.A., \& Guthrie, J.P. (2009). High performance work systems and export performance. International Journal of Human Resource Management, 20(3): 633-653. 
Martin-Tapia, I., Aragon-Correa, J.A., \& Rueda-Manzanares, A. (2010). Environmental strategy and exports in medium, small and micro-enterprises. Journal of World Business, 45(3): 266-275.

Matten, D., \& Moon, J. (2004). Corporate Social Responsibility Education in Europe. Journal of Business Ethics, 54(4): 323-337.

Matten, D., \& Moon, J. (2008). "Implicit" and "Explicit" CSR: a conceptual Framework for a comparative understanding of corporate social responsibility. Academy of Management Review, 33(2): 404-424.

Park., B.I., \& Ghauri, P.N. (2014) Determinants influencing CSR practices in small and medium sized MNE subsidiaries: A stakeholder perspective, Journal of World Business, in print.

Preuss, L., Haunschild, A., \& Matten, D. (2009). The rise of CSR: implications for HRM and employee representation. International Journal of Human Resource Management, 20(4): 953 - 973.

Ramus, C.A. (2002). Encouraging innovative environmental actions: what companies and managers must do. Journal of World Business, 37(2): 151-164.

Rehfeld, K.M., Rennings, K., \& Ziegler, A. (2007). Integrated product policy and environmental product innovations: an empirical analysis. Ecological Economics, 61(1): 91100.

Riordan, C.M., Gatewood, R.D. \& Barnes, B. (1997). Corporate Image: Employee Reactions and Implications for Managing Corporate Social Performance. Journal of Business Ethics, 16(4): 401-412.

Rugman A.M, \& Verbeke A. (1998). Corporate strategies and environmental regulations: an organizing framework. Strategic Management Journal, 19(4): 363-375. 
Russo, M., \& Fouts, P. (1997). A resource-based perspective on corporate environmental performance and profitability. Academy of Management Journal, 40, 534-559.

Schaltegger, S., \& Burritt, R.L. (2005). Corporate sustainability. In: H. Folmer \& T. Tietenberg (Eds.), The International Yearbook of Environmental and Resource Economics 2005/2006 (pp. 185-222). Boston/Cheltenham: Edward Elgar.

Schaltegger, S., \& Burritt, R.L. (2010). Sustainability accounting for companies: Catchphrase or decision support for business leaders? Journal of World Business, 45(4): 375384.

Scherer, A.G., Palazzo, G., \& Matten, D. (2009). Introduction to the Special Issue: Globalization as a Challenge for Business Responsibilities. Business Ethics Quarterly, 19(3): 327-347.

Scherer, A. G. \& Palazzo, G. (2008). Globalization and CSR. In: A. Crane, D. McWilliams, J. Moon \& D. Siegel (Eds), The Oxford Handbook of Corporate Social Responsibility. Oxford: Oxford University Press.

Scherer, A. G., \& Palazzo, G. (2011). The New Political Role of Business in a Globalized World - A Review of a New Perspective on CSR and its Implications for the Firm, Governance, and Democracy. Journal of Management Studies, 48(4): 899-931.

Scherer, A. G., Palazzo, G., \& Matten, D. (2014). The business firm as a political actor: A new theory of the firm for a globalized world. Business \& Society, 53(2): 143-156.

Smith, P.B. \& Bond, M.H. (1999). Social Psychology across Cultures. Boston: Allyn \& Bacon.

Steger U., Schindel, C., \& Krapf, H. (2002). The experience of EMAS in three European countries: a cultural and competitive analysis. Business Strategy and the Environment, 11, 32-42. 
Surroca, J., Tribo, J.A., \& Waddock, S. (2010). Intangibles, Corporate Responsibility and Financial Performance. Strategic Management Journal, 31(5): 463-490.

Tarique, I., \& Schuler, R.S. (2010). Global talent management: Literature review, integrative framework, and suggestions for further research. Journal of World Business, $45(2), 122-133$.

Turbin, D.B., \& Greening, D.W. (1997). Corporate social performance and organizational attractiveness. Academy of Management Journal, 40, 584-602.

United Nations (2011). The 6 Principles for Responsible Management Education. Accessed online at http://www.unprme.org/the-6-principles/, accessed May 7, 2011.

Waddock, S.A., \& Graves, S.B. (1997). The Corporate Social Performance - Financial Performance Link. Strategic Management Journal, 18, 303-319.

Wagner, M. (2009). National culture, regulation and country interaction effects on the association of environmental management systems with environmentally beneficial innovation. Business Strategy and the Environment, 18(2): 122-136.

Wagner, M. (2011). Environmental Management Activities and Sustainable HRM in German Manufacturing Firms - Incidence, Determinants, and Outcomes. Zeitschrift für Personalforschung, 25(2): 157-177.

Wagner (2013). “Green” Human Resource Benefits: Do they Matter as Determinants of Environmental Management System Implementation? Journal of Business Ethics, 114: $443-456$.

Wernerfelt, B. (1984). A resource-based view of the firm. Strategic Management Journal, $5,171-180$.

World Commission on Environment and Development (1987). Our Common Future. Oxford: Oxford University Press. 
World Economic Forum (WEF) (2000). Pilot Environmental Sustainability Index. Accessed online at http://www.ciesin.columbia.edu/indicators/ESI, accessed July 20, 2001. Ziegler, A., \& Rennings, K. (2004). Determinants of Environmental Innovations in Germany: Do Organizational Measures Matter? Centre for European Economic Research (Discussion Paper No. 04-30). 
TABLE 1: Estimates, EMS implementation without interactions (Hofstede)

\begin{tabular}{|c|c|c|}
\hline Variable & Coef. (Probit) & Coef. (Logit) \\
\hline Employee satisfaction & $0.45(0.06)^{* * *}$ & $0.76(0.10)^{* * *}$ \\
\hline Increased sales & $0.33(0.08)^{* * *}$ & $0.57(0.13) * * *$ \\
\hline Increased market share & $0.11(0.09)$ & $0.20(0.16)$ \\
\hline Reduced cost & $0.02(0.04)$ & $0.04(0.07)$ \\
\hline Increased productivity & $0.06(0.06)$ & $0.10(0.10)$ \\
\hline Improved insurance conditions & $0.04(0.06)$ & $0.08(0.11)$ \\
\hline Better access to bank loans & $0.13(0.11)$ & $0.27(0.18)$ \\
\hline Firm size & $0.19(0.03)^{* * *}$ & $0.33(0.04)^{* * *}$ \\
\hline Quality management system & $0.53(0.08)^{* * *}$ & $0.89(0.14)^{* * *}$ \\
\hline Overall business performance & $0.01(0.03)$ & $0.01(0.05)$ \\
\hline Market development trend & $-0.02(0.04)$ & $-0.02(0.06)$ \\
\hline Market orientation & $0.01(0.03)$ & $0.01(0.06)$ \\
\hline Firm completely independent & $-0.37(0.07)^{* * *}$ & $-0.62(0.12)^{* * * *}$ \\
\hline Food and tobacco & $0.17(0.16)$ & $0.31(0.27)$ \\
\hline Textile and leather products & $-0.04(0.89)$ & $0.27(1.68)$ \\
\hline Wood products & $0.32(0.18)^{*}$ & $0.52(0.30)^{*}$ \\
\hline Pulp and paper products & $0.34(0.18)^{*}$ & $0.59(0.29)^{* *}$ \\
\hline Publishing and printing & $0.25(0.19)$ & $0.41(0.32)$ \\
\hline Chemical products and fibres & $0.71(0.18)^{* * *}$ & $1.27(0.30)^{* * *}$ \\
\hline Rubber and plastics & $0.21(0.16)$ & $0.33(0.28)$ \\
\hline Non-ferrous mineral products & $0.05(0.23)$ & $0.16(0.41)$ \\
\hline
\end{tabular}




\begin{tabular}{lll} 
Machines and equipment & $-0.19(0.16)$ & $-0.27(0.28)$ \\
Metal products & $0.14(0.14)$ & $0.26(0.24)$ \\
Electrical devices & $0.17(0.18)$ & $0.30(0.30)$ \\
Energy, oil and gas & $0.91(0.32)^{* * *}$ & $1.49(0.55)^{* * *}$ \\
Transport products & $0.22(0.21)$ & $0.43(0.36)$ \\
Other manufacturing & $0.08(0.16)$ & $0.16(0.27)$ \\
Regulation innovativeness & $0.30(0.08)^{* * *}$ & $0.53(0.15)^{* * *}$ \\
Long-term orientation & $-0.01(0.004)$ & $-0.01(0.01)$ \\
\hline (Pseudo-) ${ }^{2}$ & 0.08 & 0.08 \\
No. of observations & 1188 & 1188 \\
F / Wald $\chi^{2}$ & $400.89 * * *$ & $392.97 * * *$
\end{tabular}

Notes: significance levels: $* \mathrm{p}<0.1 ; * * \mathrm{p}<0.05 ; * * * \mathrm{p}<0.01$; robust standard errors in parentheses 
TABLE 2: Estimates, EMS implementation with interactions (Hofstede)

\begin{tabular}{|c|c|c|}
\hline Variable & Coef. (Probit) & Coef. (Logit) \\
\hline Employee (Em.) satisfaction & $0.44(0.06)^{* * *}$ & $0.76(0.10)^{* * *}$ \\
\hline Increased sales & $0.33(0.08) * * *$ & $0.56(0.13) * * *$ \\
\hline Increased market share & $0.11(0.09)$ & $0.20(0.16)$ \\
\hline Reduced cost & $0.02(0.04)$ & $0.04(0.07)$ \\
\hline Increased productivity & $0.06(0.06)$ & $0.10(0.10)$ \\
\hline Improved insurance conditions & $0.03(0.06)$ & $0.07(0.11)$ \\
\hline Better access to bank loans & $0.13(0.11)$ & $0.29(0.19)$ \\
\hline Firm size & $0.18(0.03)^{* * *}$ & $0.31(0.05)^{* * *}$ \\
\hline Quality management system & $0.54(0.08)^{* * *}$ & $0.91(0.14)^{* * *}$ \\
\hline Overall business performance & $0.01(0.03)$ & $0.004(0.05)$ \\
\hline Market development trend & $-0.01(0.04)$ & $-0.02(0.06)$ \\
\hline Market orientation & $0.02(0.03)$ & $0.03(0.06)$ \\
\hline Firm completely independent & $-0.38(0.07)^{* * *}$ & $-0.65(0.12)^{* * *}$ \\
\hline Food and tobacco & $0.17(0.16)$ & $0.30(0.27)$ \\
\hline Textile and leather products & $-0.08(0.89)$ & $0.20(1.68)$ \\
\hline Wood products & $0.30(0.18)^{*}$ & $0.48(0.29)$ \\
\hline Pulp and paper products & $0.34(0.18)^{*}$ & $0.59(0.29)^{* *}$ \\
\hline Publishing and printing & $0.25(0.19)$ & $0.41(0.32)$ \\
\hline Chemical products and fibres & $0.70(0.18)^{* * *}$ & $1.25(0.29)^{* * *}$ \\
\hline Rubber and plastics & $0.20(0.16)$ & $0.33(0.28)$ \\
\hline Non-ferrous mineral products & $0.06(0.23)$ & $0.15(0.41)$ \\
\hline
\end{tabular}


Machines and equipment

Metal products

Electrical devices

Energy, oil and gas

Transport products

Other manufacturing

Regulation innovativeness

Long-term orientation

Market orientation*Firm size

Regulatory innovativeness*Em. satisfaction

Long-term orientation*Em. Satisfaction

(Pseudo-) $\mathrm{R}^{2}$

No. of observations

Wald $\chi^{2}$
$-0.20(0.16)$

$-0.30(0.28)$

$0.13(0.14)$

$0.25(0.24)$

$0.15(0.18)$

$0.29(0.30)$

$0.90(0.32) * * *$

$1.50(0.55)^{* * *}$

$0.20(0.21)$

$0.39(0.36)$

$0.08(0.16)$

$0.18(0.27)$

$0.30(0.08)^{* * *}$

$0.53(0.15)^{* * *}$

$-0.01(0.004)$

$-0.01(0.01)$

$0.05(0.03)^{*}$

$0.10(0.05)^{* *}$

$0.02(0.13)$

$0.08(0.22)$

$-0.004(0.01)$

$-0.01(0.01)$

0.08

0.08

1188

1188

402.86***

Notes: significance levels: $* \mathrm{p}<0.1 ; * * \mathrm{p}<0.05 ; * * * \mathrm{p}<0.01$; robust standard errors in parentheses 
TABLE 3: Estimates, EMS implementation without interaction (World Values)

\begin{tabular}{|c|c|c|}
\hline Variable & Coef. (Probit) & Coef. (Logit) \\
\hline Employee satisfaction & $0.44(0.06) * * *$ & $0.73(0.10)^{* * *}$ \\
\hline Increased sales & $0.32(0.08) * * *$ & $0.55(0.13)^{* * *}$ \\
\hline Increased market share & $0.10(0.09)$ & $0.17(0.16)$ \\
\hline Reduced cost & $0.02(0.04)$ & $0.05(0.07)$ \\
\hline Increased productivity & $0.06(0.06)$ & $0.10(0.10)$ \\
\hline Improved insurance conditions & $0.06(0.06)$ & $0.13(0.11)$ \\
\hline Better access to bank loans & $0.10(0.11)$ & $0.21(0.18)$ \\
\hline Firm size & $0.19(0.03)^{* * *}$ & $0.33(0.04)^{* * *}$ \\
\hline Quality management system & $0.53(0.08)^{* * *}$ & $0.89(0.13)^{* * *}$ \\
\hline Overall business performance & $0.01(0.03)$ & $0.004(0.05)$ \\
\hline Market development trend & $-0.02(0.03)$ & $-0.03(0.06)$ \\
\hline Market orientation & $0.02(0.03)$ & $0.02(0.06)$ \\
\hline Firm completely independent & $-0.34(0.07) * * *$ & $-0.58(0.11)^{* * *}$ \\
\hline Food and tobacco & $0.16(0.16)$ & $0.29(0.27)$ \\
\hline Textile and leather products & $-0.13(0.88)$ & $0.15(1.64)$ \\
\hline Wood products & $0.24(0.18)$ & $0.37(0.30)$ \\
\hline Pulp and paper products & $0.33(0.17)^{*}$ & $0.57(0.29)^{*}$ \\
\hline Publishing and printing & $0.27(0.19)$ & $0.46(0.32)$ \\
\hline Chemical products and fibres & $0.72(0.18)^{* * *}$ & $1.29(0.30)^{* * *}$ \\
\hline Rubber and plastics & $0.18(0.16)$ & $0.29(0.28)$ \\
\hline Non-ferrous mineral products & $0.07(0.23)$ & $0.20(0.41)$ \\
\hline
\end{tabular}


Machines and equipment

$-0.22(0.16)$

$-0.33(0.28)$

Metal products

$0.10(0.15)$

$0.19(0.24)$

Electrical devices

$0.20(0.18)$

$0.37(0.30)$

Energy, oil and gas

$1.03(0.30)^{* * *}$

$1.71(0.49)^{* * *}$

Transport products

$0.22(0.21)$

$0.45(0.35)$

Other manufacturing

$0.10(0.16)$

$0.21(0.27)$

Regulation innovativeness

$0.03(0.14)$

$0.02(0.25)$

Secular-rational value orientation

$0.31(0.07)^{* * *}$

$0.51(0.13)^{* * *}$

Self-expression value orientation

$0.14(0.10)$

$0.28(0.18)$

(Pseudo-)R ${ }^{2}$

0.08

0.08

No. of observations

1188

1188

F / Wald $\chi^{2}$

$434.26 * * *$

$432.10 * * *$

Notes: significance levels: $* \mathrm{p}<0.1$; $* * \mathrm{p}<0.05 ; * * * \mathrm{p}<0.01$; robust standard errors in parentheses 
TABLE 4: Estimates, EMS implementation without interaction (World Values)

\begin{tabular}{|c|c|c|}
\hline Variable & Coef. (Probit) & Coef. (Logit) \\
\hline Employee satisfaction & $0.43(0.06)^{* * *}$ & $0.74(0.10)^{* * *}$ \\
\hline Increased sales & $0.32(0.08) * * *$ & $0.55(0.13)^{* * *}$ \\
\hline Increased market share & $0.09(0.09)$ & $0.16(0.16)$ \\
\hline Reduced cost & $0.02(0.04)$ & $0.05(0.07)$ \\
\hline Increased productivity & $0.06(0.06)$ & $0.10(0.10)$ \\
\hline Improved insurance conditions & $0.06(0.06)$ & $0.11(0.11)$ \\
\hline Better access to bank loans & $0.10(0.11)$ & $0.22(0.18)$ \\
\hline Firm size & $0.19(0.03) * * *$ & $0.32(0.05)^{* * *}$ \\
\hline Quality management system & $0.54(0.08) * * *$ & $0.92(0.13)^{* * *}$ \\
\hline Overall business performance & $0.01(0.03)$ & $0.1(0.05)$ \\
\hline Market development trend & $-0.03(0.04)$ & $-0.04(0.06)$ \\
\hline Market orientation & $0.03(0.03)$ & $0.05(0.06)$ \\
\hline Firm completely independent & $-0.35(0.07)^{* * *}$ & $-0.60(0.12)^{* * *}$ \\
\hline Food and tobacco & $0.18(0.16)$ & $0.33(0.26)$ \\
\hline Textile and leather products & $-0.11(0.88)$ & $0.18(1.64)$ \\
\hline Wood products & $0.23(0.18)$ & $0.37(0.29)$ \\
\hline Pulp and paper products & $0.34(0.17)^{*}$ & $0.59(0.28)^{* *}$ \\
\hline Publishing and printing & $0.28(0.19)$ & $0.50(0.32)$ \\
\hline Chemical products and fibres & $0.73(0.18)^{* * *}$ & $1.33(0.30)^{* * *}$ \\
\hline Rubber and plastics & $0.17(0.16)$ & $0.27(0.27)$ \\
\hline Non-ferrous mineral products & $0.07(0.23)$ & $0.19(0.41)$ \\
\hline
\end{tabular}




\begin{tabular}{|c|c|c|}
\hline Machines and equipment & $-0.22(0.16)$ & $-0.34(0.27)$ \\
\hline Metal products & $0.11(0.15)$ & $0.20(0.24)$ \\
\hline Electrical devices & $0.20(0.18)$ & $0.38(0.30)$ \\
\hline Energy, oil and gas & $1.06(0.30)^{* * *}$ & $1.76(0.47)^{* * *}$ \\
\hline Transport products & $0.21(0.21)$ & $0.45(0.35)$ \\
\hline Other manufacturing & $0.11(0.16)$ & $0.24(0.27)$ \\
\hline Regulation innovativeness & $0.04(0.14)$ & $0.03(0.25)$ \\
\hline Secular-rational value orientation & $0.30(0.07)^{* * *}$ & $0.50(0.13)^{* * *}$ \\
\hline Self-expression value orientation & $0.14(0.10)$ & $0.28(0.18)$ \\
\hline Market orientation*firm size & $0.05(0.03)^{*}$ & $0.09(0.05)^{*}$ \\
\hline Regulatory innovativeness*Em. satisfaction & $0.40(0.23)^{*}$ & $0.87(0.41)^{* *}$ \\
\hline Secular-rational orientation*Em. satisfaction & $-0.02(0.13)$ & $-0.03(0.22)$ \\
\hline Self-expression orientation*Em. satisfaction & $-0.33(0.16)^{* *}$ & $-0.67(0.29)^{* *}$ \\
\hline (Pseudo-)R $\mathrm{R}^{2}$ & 0.08 & 0.08 \\
\hline No. of observations & 1188 & 1188 \\
\hline F / Wald $\chi^{2}$ & $438.23 * * *$ & $439.32 * * *$ \\
\hline
\end{tabular}


TABLE 5: Overall findings of testing the system of research hypotheses

\begin{tabular}{ll}
\hline Research hypothesis & Test result \\
\hline 1 & supported \\
2 & supported \\
$3(\mathrm{a}, \mathrm{b})$ & not supported \\
$4(\mathrm{a}, \mathrm{b})$ & supported \\
$5(\mathrm{a}, \mathrm{b})$ & partially supported \\
\hline
\end{tabular}


TABLE A1: Overview of sectoral and country distribution of respondents

\begin{tabular}{|c|c|c|c|c|c|c|c|c|c|}
\hline $\begin{array}{l}\text { Country } \\
\text { Industry }\end{array}$ & NL & GER & SWE & $\mathbf{C H}$ & UK & FRA & BEL & NOR & HUN \\
\hline Food products, tobacco & 55 & 39 & 20 & 13 & 6 & 2 & 37 & 28 & 27 \\
\hline Textile products & 6 & 15 & 6 & 5 & 7 & 11 & 17 & 8 & 33 \\
\hline Leather products & 0 & 0 & 1 & 0 & 1 & 1 & 1 & 0 & 11 \\
\hline Wood products & 10 & 1 & 29 & 3 & 6 & 3 & 15 & 10 & 7 \\
\hline Pulp \& paper products & 14 & 11 & 12 & 3 & 3 & 4 & 9 & 9 & 11 \\
\hline Publishing \& printing & 18 & 23 & 18 & 3 & 14 & 4 & 7 & 12 & 0 \\
\hline Energy; cokes, oil fuel & 3 & 2 & 0 & 1 & 3 & 3 & 1 & 0 & 9 \\
\hline Chemical products, fibers & 16 & 24 & 17 & 13 & 18 & 23 & 32 & 10 & 10 \\
\hline Rubber and plastic & 28 & 16 & 19 & 11 & 5 & 10 & 17 & 7 & 11 \\
\hline Non-ferrous mineral products & 12 & 17 & 1 & 3 & 4 & 3 & 15 & 8 & 16 \\
\hline Metal products & 94 & 44 & 78 & 18 & 23 & 30 & 48 & 35 & 16 \\
\hline Machines \& equipment & 30 & 35 & 30 & 12 & 12 & 22 & 15 & 7 & 20 \\
\hline Electrical \& optical equipment & 12 & 34 & 15 & 17 & 13 & 10 & 8 & 9 & 8 \\
\hline Transport products & 6 & 17 & 6 & 1 & 9 & 12 & 6 & 2 & 10 \\
\hline Other & 56 & 56 & 34 & 9 & 54 & 4 & 54 & 8 & 3 \\
\hline
\end{tabular}

Notes: NL - Netherlands; GER - Germany; SWE - Sweden; CH - Switzerland; UK -Great Britain; FRA

- France; BEL - Belgium; NOR - Norway; HUN - Hungary 
TABLE A2: Descriptive statistics and correlations

\begin{tabular}{|c|c|c|c|c|c|c|c|c|c|c|c|c|c|c|c|c|c|c|c|}
\hline Variable & Mean & SD & 1. & 2. & 3. & 4. & 5. & 6. & 7. & 8. & 9. & 10. & 11. & 12. & 13. & 14. & 15. & 16. & 17. \\
\hline 1. EMS implementation & 5.78 & 3.37 & & & & & & & & & & & & & & & & & \\
\hline 2. Employee satisfaction & 3.69 & 0.57 & $0.32 * * *$ & & & & & & & & & & & & & & & & \\
\hline 3. Increased sales & 3.29 & 0.51 & $0.25 * * *$ & $0.23 * *$ & & & & & & & & & & & & & & & \\
\hline 4. Market share & 3.19 & 0.45 & $0.23 * * *$ & $0.20 * * *$ & $0.68 * * *$ & & & & & & & & & & & & & & \\
\hline 5. Reduced cost & 3.29 & 0.84 & $0.15 * * *$ & $0.16^{* * *}$ & $0.09 * * *$ & $0.10 * * *$ & & & & & & & & & & & & & \\
\hline 6. Increased productivity & 3.14 & 0.60 & $0.17 * * *$ & $0.27 * * *$ & $0.20 * * *$ & $0.21 * * *$ & $0.45 * * *$ & & & & & & & & & & & & \\
\hline 7. Insurance conditions & 3.30 & 0.55 & $0.15 * * *$ & $0.26 * * *$ & $0.15 * * *$ & $0.18 * * *$ & $0.19 * * *$ & $0.21 * * *$ & & & & & & & & & & & \\
\hline 8. Bank loan access & 3.07 & 0.34 & $0.13 * * *$ & $0.15 * * *$ & $0.19 * * *$ & $0.22 * * *$ & $0.15 * * *$ & $0.15 * * *$ & $0.41 * * *$ & & & & & & & & & & \\
\hline 9. Firm size & 5.33 & 1.29 & $0.27 * * *$ & $0.10 * * *$ & 0.01 & $0.05 *$ & $0.14 * * *$ & $0.09 * * *$ & $0.14 * * *$ & $0.13 * * *$ & & & & & & & & & \\
\hline 10. QMS & 0.77 & 0.42 & $0.31 * * *$ & $0.12 * * *$ & $0.10 * * *$ & $0.09 * * *$ & $0.09 * * *$ & $0.07 * *$ & $0.08 * * *$ & 0.04 & $0.20 * * *$ & & & & & & & & \\
\hline 11. Performance & 3.87 & 1.01 & $0.08 * * *$ & $0.07 * *$ & $0.08 * * *$ & $0.10 * * *$ & $0.07 * *$ & $0.10 * * *$ & $0.09 * * *$ & $0.05^{*}$ & $0.07 * * *$ & $0.12 * * *$ & & & & & & & \\
\hline 12. Market trend & 3.35 & 0.95 & 0.05 & $0.06 * *$ & $0.12 * * *$ & $0.13 * * *$ & $0.06^{* *}$ & $0.06 * *$ & $0.06 *$ & $0.08 * * *$ & 0.04 & $0.07 * *$ & $0.28 * * *$ & & & & & & \\
\hline 13. Firm independent & 0.36 & 0.48 & $-0.22 * * *$ & $-0.10 * * *$ & 0.001 & -0.04 & $-0.09 * * *$ & $-0.06 * *$ & -0.03 & 0.0001 & $-0.06 * *$ & $-0.18 * *$ & -0.03 & -0.02 & & & & & \\
\hline 14. Regulation innovative. & 1.07 & 0.42 & $0.13 * * *$ & -0.005 & 0.01 & 0.01 & $0.12 * * *$ & 0.02 & $-0.10 * * *$ & $-0.08 * * *$ & $-0.10 * * *$ & $0.10 * * *$ & 0.04 & 0.04 & $-0.11 * * *$ & & & & \\
\hline 15. Long-term orientation & 34.9 & 7.70 & $-0.05^{*}$ & -0.03 & $-0.06 * *$ & $-0.05^{*}$ & $-0.07 * *$ & $-0.05 *$ & -0.001 & 0.02 & 0.02 & -0.003 & $0.08 * * *$ & $0.17 * * *$ & $-0.08 * * *$ & $-0.06 * *$ & & & \\
\hline 16. Secular-rational orient. & 0.95 & 0.44 & $0.19 * * *$ & $0.09 * * *$ & $0.10 * * *$ & $0.10 * * *$ & $0.10 * * *$ & $0.05^{*}$ & -0.05 & 0.03 & $-0.05^{*}$ & $0.08 * * *$ & 0.02 & -0.01 & $-0.06 * *$ & $0.39 * * *$ & $-0.27 * * *$ & & \\
\hline 17. Self-expression orient. & 1.48 & 0.60 & $0.14 * * *$ & -0.004 & 0.04 & 0.02 & $0.06^{* *}$ & 0.01 & $-0.12 * * *$ & $-0.06 * *$ & $-0.15 * * *$ & $0.07 * *$ & 0.02 & $0.09 * * *$ & $-0.20 * * *$ & $0.80 * * *$ & $0.13 * * *$ & $0.36 * * *$ & \\
\hline 18. Market Orientation & 4.15 & 0.98 & $0.11 * * *$ & $0.09 * * *$ & -0.01 & 0.01 & $0.07 * *$ & $0.05^{*}$ & $0.08 * * *$ & $0.05^{*}$ & $0.19 * * *$ & $0.16 * * *$ & 0.04 & $0.18 * * *$ & $-0.11 * * *$ & 0.04 & $0.11 * * *$ & $-0.05^{*}$ & 0.04 \\
\hline
\end{tabular}

